\title{
Heat and drought resistance criteria in spring bread wheat (Triticum aestivum L.): Morpho-physiological parameters for heat tolerance
}

\author{
Bilge Bahar $^{1 \star}$, Mehmet Yildirim ${ }^{2}$ and Cemal Yucel ${ }^{3}$ \\ ${ }^{1}$ Siran Vocational School, Gumushane University, Gumushane, 29700 Turkey. \\ ${ }^{2}$ Field Crops Department, Agricultural Faculty, Dicle University, Diyarbakir, 21280 Turkey. \\ ${ }^{3}$ Field Crops Department, Agricultural Faculty, Cukurova University, Adana, 01330 Turkey.
}

Accepted 6 May, 2011

\begin{abstract}
This study was aimed at evaluating some morpho-physiological parameters such as stomatal conductance $\left(g_{s}\right)$, canopy temperature (CT), canopy temperature depression (CTD) and stay green duration (SGD) in terms of heat tolerance. For this purpose, trials designed according to randomized complete blocks were conducted with twenty-four spring bread wheat genotypes as three replicated in the Research and Application Area of Field Crops Department of Agricultural Faculty of Cukurova University in 2002 to 2003 and 2003 to 2004 growth seasons. The measurements of $g_{s}$ were made at two different dates at heading stage in 2003 to 2004 growth season. CT was measured at two growth stages (late milky and soft dough) in 2002 to 2003 (first) season and it was also measured at two different hours at the complete heading stage in 2003 to 2004 (second) season. CTD was measured at two different hours at the complete heading stage in the second season. The other morpho- physiological parameter was SGD, which was determined in the first growth season. As a result: (1) The high $\mathrm{g}_{s}$ values were observed at both measuring dates even though there was no significant differences among the genotypes; (2) CT showed significant differences except T2 measurement in 2003 to 2004 season, yet significant negative correlations were found between CT and grain yield (GY) in 2003 to 2004 season and in general mean; (3) Despite not being significant differences among the genotypes, a strong positive correlation was found between CTD and GY; (4) In spite of the fact that genotypes did not show any statistical differences, it was found that SGD had a negative significant correlation with CT but positive non-significant correlation with GY. It is concluded from assessments of all physiological traits that such genotypes as Kauz/Altar 84//Ads, Varona Cno 79, Mon's'/Ald's'//Bow's' and WL6718 can be high yielding even if under heat stressed conditions, and can be used as gene pool in wheat breeding programs for tolerance to heat stress.
\end{abstract}

Key words: Spring bread wheat (Triticum aestivum L.), canopy temperature, stomatal conductance, stay green, heat stress tolerance.

\section{INTRODUCTION}

In recent years, wheat grain requirements of developing countries have increased with $2 \%$ (Curtis, 2002); however, increases of genetic gains are low in spring and winter wheats, respectively 1 and $0.5 \%$ (Donmez et al., 2001). Even if there are increases in the yield potential by

*Corresponding author. E-mail: bilgebahar@gmail.com. Tel: (+90) 456511 8669. Fax: (+90) 4565118679. wheat breeding, the success of the future depends on the cooperation between wheat breeders and crop physiologists (Jackson et al., 1996). It is known that the most important abiotic stress factors are heat and drought stress, which affect the crop physiogical traits. Thus, the yield of wheat is limited under stress conditions; other factors are even optimum levels. If heat stress occurs during the post-anthesis (grain filling period), it has a negative influence on the movement of photosynyhetic products to the developing kernels and inhibits the starch 
synthesis; thus, it causes lower grain weight also lower yield and alters grain quality (Bhullar and Jenner, 1985). In addition, for the healty wheat growth and a good yield, the range of optimum temperatures is 18 to $24^{\circ} \mathrm{C}$. Over these ranges $\left(28\right.$ to $32^{\circ} \mathrm{C}$ ) even 5 to 6 days short periods cause $20 \%$ or more yield losses in wheat (Stone and Nicolas, 1994). Also, Acevedo et al. (1991) have reported that every $1{ }^{\circ} \mathrm{C}$ increase over 17 to $24^{\circ} \mathrm{C}$ in avarage temperature during grain filling causes four percent yield reduction in grain weight from yield components. Wheat yield is mainly limited by heat stress in arid, semi-arid, tropical, and sub-tropical areas (Fischer, 1986).

In recent years, researchers show that some physiological criteria such as stomatal conductance (Bahar et al., 2009), photosynthetic rate (Koc et al., 2003), membran thermal stability (Yıldırım et al., 2009), canopy temperature depression (Bahar et al., 2008), and cholorophyll content (Yıldırım et al., 2011) provide a gain on wheat. However, yield and yield components are still been used as most effective screening criteria in wheat under heat stressed conditions (Ozkan et al., 1998; Mohammadi et al., 2004). Physiological researches showed that photosynthetic rate of flag leaf, stomatal conductance, and ash content were the complementary selection criteria for heat stress tolerance under Mediterranean conditions (Koc et al., 2008). It had been pronounced that CTD is usually expressed as canopy temperature (Tc) minus air temperature ( $\mathrm{Ta}$ ), and it is positive when the canopy is cooler than the air. It has been used as a selection criterion in wheat breeding in terms of heat and drought stress tolerance (Reynolds et al., 2001; Balota et al., 2007). According to Munjal and Rana (2003), cooler canopy and high stomatal conductance at grain filling period would be assumed as the basic morpho-physiological criteria for higher grain yield under heat stressed conditions. Balota et al. (2008) reported that wheat cultivarswith high CTD showed a trend of higher yield under heat and drought stress. Bahar et al. (2008) showed durum wheat (Triticum durum L.) stayed cooler than bread wheat genotypes under heat stress conditions.

They also found positive significant correlation between CTD and grain yield $\left(r=0.45^{*}, P \leq 0.05\right)$ at half of heading stage; but non-significant positive correlation $(r=$ 0.39 ) at completed anthesis in bread wheat under heat stress in the Mediterranean region. CTD was mostly high positive significant correlated with grain yield (Amani et al., 1996; Ayeneh et al., 2002) and stomatal conductance (Amani et al., 1996). CTD was correlated with yield under drought stress (Blum, 1988), and heat, irrigated conditions (Reynolds et al., 1994; Amani et al., 1996). Ginkel et al. (2004) reported that overall CTD showed relative high correlation with yield under more optimum (irrigated) conditions $(r=0.74, P \leq 0.001)$. They also recommended that CTD could be used to identify plants with cooler canopies with the aim of yield increasing under non-stressed conditions. Another physiological parameter for heat stress tolerance is stomatal conductance $\left(g_{s}\right)$. Anjum et al. (2008) reported that transpiration of flag leaf has increased by $g_{s}$; thus, leaves will be cooler with transpiration at high temperature. Fischer et al. (1998) investigated the physiological basis of the associations of CTD and stomatal conductance with grain yield. They found the greatest correlation between $g_{s}$ and grain yield $(r=0.94, P \leq 0.01)$ and compared the mean yield, $g_{s}$ and CTD. The result showed that yield increase was $27 \%$ while $g_{s}$ increase $63 \%$ and canopies were $0.6^{\circ} \mathrm{C}$ cooler.

Canopy temperatures are determina-tive as CTD for heat tolerance. In the same way, Siddique et al. (2000) observed the canopy temperature between 23.89 and $29.18^{\circ} \mathrm{C}$ at anthesis. They also reported that plants under drought stress showed higher canopy temperature than non-stressed (well-watered) plants at both vegetative and anthesis stages. However, Singh and Kanemasu (1983) announced pearl millet (Pennisetum glaucum L.) genotypes showed significantly higher yield with warmer canopy temperature (CT) under irrigated conditions than with cooler CT under non-irrigated conditions. Bahar et al. (2009) have reported that $g_{s}$ values have shown positive correlations with grain yield at early milky maturity stage when the genotypes have been classified according to their phenologies at anthesis as earlier or later group. On the other hand, Anjum et al. (2008) found non-significant correlations between grain yield and stomatal conductance.

It is known that staying green is related to heat tolerance (Blum and Neguyen, 1997). It was stressed that healthy stay-green plants are more producable for grain yield (Ban bella and Paulson, 1998; Thomas and Smart, 1993). Kumar et al. (2010) have reported that stay green or delayed senescence is considered to play a crucial role in grain development in wheat when assimilates are limited, and stay green cultivars are well adapted to drought and heat stressed conditions. Kumari et al. (2007) screened some Indian and Cimmyt germplasms for the visible or non-visible stay green (SG) which was evaluated on visual scoring (0 to 9 scale). They found significant differences between SG and non-SG genotypes for CTD. They also reported that SG together with CTD could be used as an effective selection criterion for heat stress tolerance. Acceleration of leaf senescence by increased temperature reduces leaf viability and photosynthetic activity (Harding et al., 1990).

This study was conducted (1) to evaluate some morpho-physiological criteria for heat tolerance; (2) to determine the relationships of these criteria with each other and grain yield in spring bread wheat under the Mediterranean conditions, and (3) to advise on genotypes to be used as heat tolerant in wheat breeding programs.

\section{MATERIALS AND METHODS}

Field trials were conducted at Field Crops Department Research 


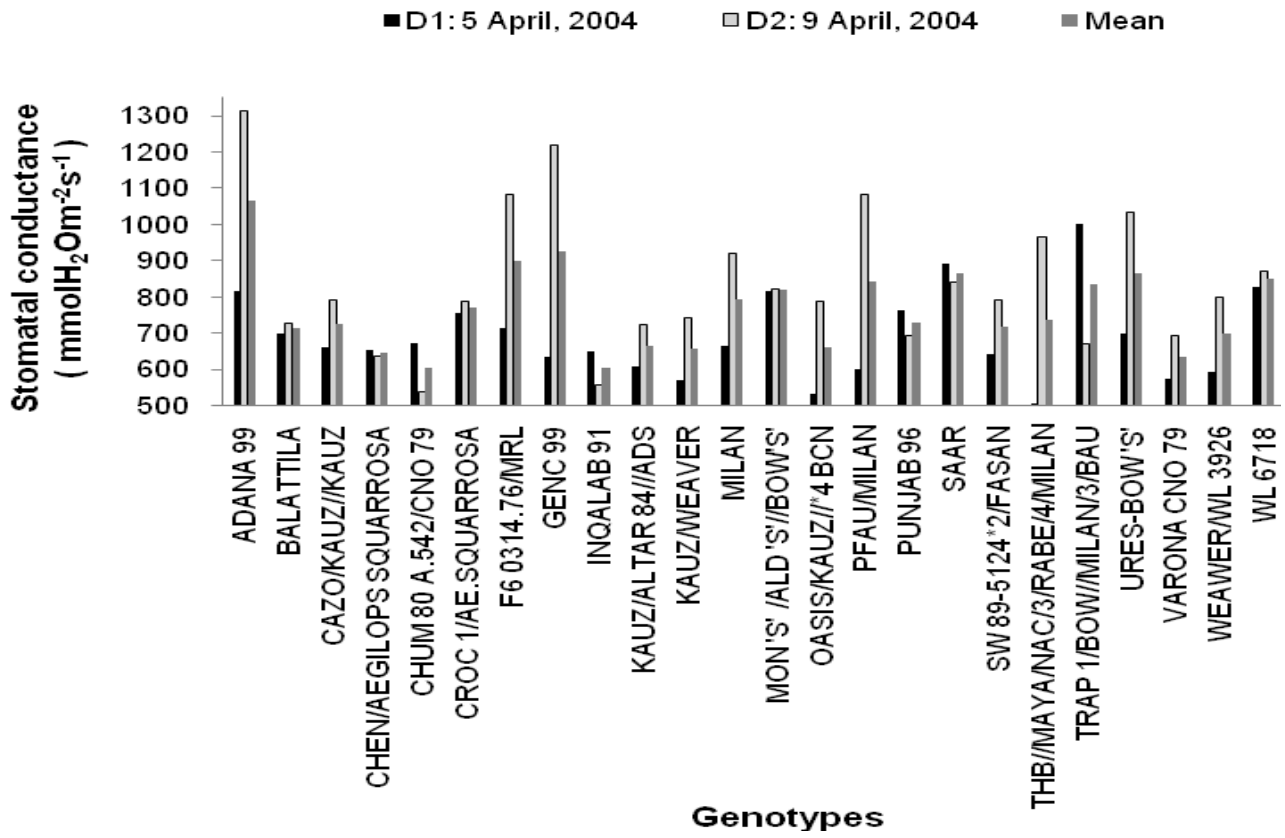

Figure 1. Changes in the measurements of the stomatal conductance of flag leaf of 24 bread wheat genotypes in 2003 to 2004 growth season. LSD is not significant at 0.05 probability for both measuring dates (D1 and D2) and their mean.

Area (Latitude: $41^{\circ} 04^{\prime} \mathrm{N}$, Longitude: $36^{\circ} 71^{\prime} \mathrm{E}$, and Altitude: $36 \mathrm{~m}$ ), Agricultural Faculty, University of Cukurova, during the 2002 to 2003 and 2003 to 2004 growth seasons. Trial was designed according to complete randomized blocks with three replications. Twenty-four bread wheat (Triticum aestivum L.) genotypes were used as material. Cultivars Adana 99, Balattila, Genc 99, Inqalab 91. Milan, Punjab 96 and Saar are CIMMYT originated, and the other genotypes have been obtained from CIMMYT. Seeds were sown with a plot drill (Hege-80) at the first week of December at both seasons. Trial plots were $6 \mathrm{~m}^{-2}(5 \times 1.2 \mathrm{~m}$ sizes), and sowing density was 450 seeds $\mathrm{m}^{-2}$. All of phosphorus $\left(80 \mathrm{~kg} \mathrm{ha}^{-1}, \mathrm{P}_{2} \mathrm{O}_{5}\right)$ and half of total nitrogen $\left(80 \mathrm{~kg} \mathrm{ha}^{-1}, \mathrm{~N}\right)$ was applied at sowing time. The other half of $\mathrm{N}$ was split and given at tillering (as urea) and booting (as ammonium nitrate) stages, respectively. Weeds were controlled by hand, and no-irrigation was applied during growth seasons. The trial was harvested at the first week of June in both growth seasons with a Hege-125 harvester machine.

In the growth season of 2002 to 2003, maximum temperatures on the measure dates (at the grain filling period), $6^{\text {th }}$ May and $10^{\text {th }}$ May, were 35.0 and $36.8^{\circ} \mathrm{C}$, respectively. In 2003 to 2004 growth season, maximum temperatures on the measure dates (at the heading stages), $5^{\text {th }}, 9^{\text {th }}$ and $11^{\text {th }}$ April, were $20.9,27.8$ and $31.0^{\circ} \mathrm{C}$, respectively. In addition, in the reproductive period of wheat, relative humidity in 2002 to 2003 season $(62.5 \%)$ was similar to 2003 to 2004 season (65.7\%). In the growth season of 2003 to 2004 , total precipitation higher $(587 \mathrm{~mm})$ than the previous growth season (2002 to 2003, with $442 \mathrm{~mm}$ ). However, 2003 to 2004 growth season had lower rainfall $(65 \mathrm{~mm})$ than the previous growth season $(168 \mathrm{~mm})$ for generative period of the growth season (anthesis to ripening). Furthermore, the day numbers over $30^{\circ} \mathrm{C}$ during grain filling period were 22 and 5 for first season (2002 to 2003) and second season (2003 to 2004), respectively.

Stomatal conductance $\left(g_{s}\right)$ was measured by diffusion porometer (AP4-Delta-T Eijelkampt, Giesbech, The Netherlands) on the top surface of the flag leaf as mmol $\mathrm{H}_{2} \mathrm{O} \mathrm{m} \mathrm{m}^{-2} \mathrm{~s}^{-1}$. Measurements were realized at two dates $\left(5^{\text {th }}\right.$ April and $9^{\text {th }}$ April, 2004) at the heading stages (ZGS 5.4, half of the heading and ZGS 5.8, complete heading) according to Zadoks Growth Scale (Zadoks et al., 1974) at full clear air conditions between 10:00 am and 16:00 pm, nearly 1500 PAR light intensity.

Canopy temperatures were measured on two dates $\left(6^{\text {th }}\right.$ and $10^{\text {th }}$ May, 2003) by infrared thermometer at late milky (ZGS 7.3) and soft dough (ZGS 8.5) stages in 2002 to 2003 season, and at two periods (12:00 to $13: 00 \mathrm{~h}$ and 14:00 to $15: 00 \mathrm{~h}$ ) at the end of heading stage (ZGS 5.8) in 2003 to 2004 growth season.

CTD measurements were made by infrared thermometer (Model IRTS-P, Apogee Instrument, Inc., Logan, UT, USA) which was focused to $5: 1 \mathrm{~m}$ at early afternoon cloudless periods (12:00 to 15:00 h). As similar to method of Fischer et al. (1998), the data of each plot were the mean of four readings, taken from the same side of each plot at an angle of approximately $30^{\circ}$ to the horizontal in a range of directions such that they covered different regions of the plot and integrated many leaves. In addition, measurements were at two times (12:00 to $13: 00 \mathrm{pm}$ and $14: 00$ to $15: 00 \mathrm{pm}$ ) at the heading stage (ZGS 5.8) in 2003 to 2004 growth season.

Stay green duration (SGD) was determined as a period between sowing date and turning time to yellowing of each genotype's flag leaf. It is observed for only 2002 to 2003 growth season.

Variance analysis and multiple comparisons of data with Duncan multiple range test, and correlations among characters were made by JMP statistical software (2007).

\section{RESULTS AND DISCUSSIONS}

\section{Stomatal conductance}

Stomatal conductance $\left(\mathrm{g}_{\mathrm{s}}\right)$ was measured on two dates, $5^{\text {th }}$ April (ZGS 54, half of heading) and $9^{\text {th }}$ April (ZGS 58, complete heading) in 2003 to 2004 growth season, and genotypes did not show statistically differences for $g_{s}$ on both dates and their mean (Figure 1). Nevertheless $g_{s}$ 


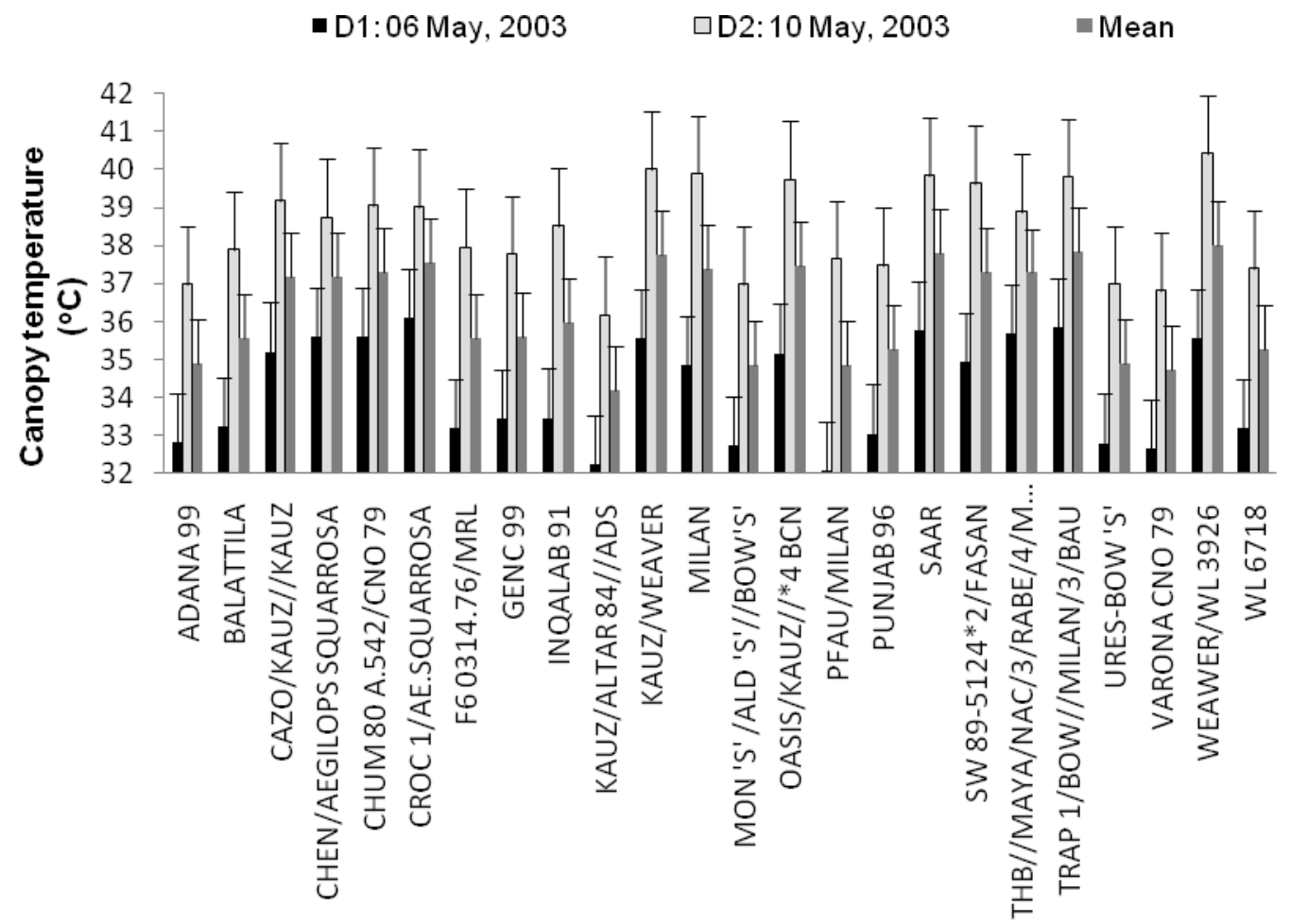

Genotypes

Figure 2. Changes in the measurements of the canopy temperatures of 24 bread wheat genotypes in 2002 to 2003 growth season. D1 and D2 show the measuring dates at the stages of late milky (ZGS 7.3) and soft dough (ZGS 8.5), respectively. Error bars indicate LSD at 0.05 probability.

values ranged from $505 \mathrm{mmol} \mathrm{H}_{2} \mathrm{O} \mathrm{m} \mathrm{m}^{-2} \mathrm{~s}^{-1}$ (line $\mathrm{Thb} / \mathrm{Maya} / \mathrm{Nac} / 3 /$ Rabe/4/Milan) to $1003 \mathrm{mmol} \mathrm{H}_{2} \mathrm{O} \mathrm{m} \mathrm{m}^{-2}$ (line Trap 1/Bow//Milan/3/Bau) at ZGS 54. At the stage of ZGS 58, $g_{\mathrm{s}}$ measurements were found between 539 mmol $\mathrm{H}_{2} \mathrm{O} \mathrm{m} \mathrm{m}^{-1}$ (line Chum 80A.542/Cno 79) and 1314 $\mathrm{mmol} \mathrm{H}_{2} \mathrm{O} \mathrm{m} \mathrm{m}^{-2}$ (cv. Adana-99). Also, gs values for mean measure dates ranged from $603 \mathrm{mmol} \mathrm{H}_{2} \mathrm{O} \mathrm{m}^{-2} \mathrm{~s}^{-1}$ in cv. Inqalab 91 to $1066 \mathrm{mmol} \mathrm{H}_{2} \mathrm{O} \mathrm{m}^{-2} \mathrm{~s}^{-1}$ in cv. Adana99 (Figure 1).

Results revealed that all genotypes showed high measure values at heading stage (at both measure dates) for $g_{s}$. In the study of Bahar et al. (2009), there were lower $g_{\mathrm{s}}$ values at the grain filling periods like early milk $\left(294 \mathrm{mmolH}_{2} \mathrm{Om}^{-2} \mathrm{~s}^{-1}\right)$, late milk $\left(225 \mathrm{mmol} \mathrm{H}_{2} \mathrm{O} \mathrm{m}{ }^{-2} \mathrm{~s}\right.$ $\left.{ }^{1}\right)$, and early dough maturity $\left(167 \mathrm{mmol} \mathrm{H}_{2} \mathrm{O} \mathrm{m} \mathrm{s}^{-1} \mathrm{~s}^{-1}\right.$ ). The reason of this difference was stomatal conductance values of flag leaves have rapidly decreased by the leaf senescence after anthesis period. In addition, Rees et al. (1993) and Delgado et al. (1994) have reported similar findings. They have observed high $g_{s}$ values at preanthesis, but not at post-anthesis stages.

\section{Canopy temperature}

Genotypes showed statistically significant differences for canopy temperature (CT) measurements at late milky and soft dough stages, and their mean in 2002 to 2003 season (Figure 2). In 2002 to 2003 growth seasons, CT values at late milky stage changed between 32.07 and $36.10^{\circ} \mathrm{C}$. The lowest CT values were observed in Pfau/Milan, Kauz/Altar84//Ads, Varona Cno 79, Monus'/Ald's'//Bow's', and Adana-99 while the highest CT values were in Cazo/Kauz//Kauz, Kauz/Weawer, Weawer/WL 3926, Chen/Aegilops squarrosa, $\mathrm{Thb} / / \mathrm{Maya} / \mathrm{Nac} / 3 /$ Rabe/4/Milan, Saar, Trap1/Bow//Milan/3/Bau, and Croc1/Aegilops squarrosa. CT measurements at soft dough stage ranged from 36.18 to $40.43^{\circ} \mathrm{C}$ (Figure 1). The lowest CT values were noticed in Kauz/Atlar 84//Ads, Varona Cno 79, Mon's'/Ald's'//Bow's', and Adana-99 while the highest CT measurements were observed in Trap1/Bow//Milan/3/Bau, Saar, Milan, Kauz/Weawer, and Weawer/WL 3926. As mean of stages (late milky and soft dough), CT values of genotypes showed differences between 34.21 and $37.99^{\circ} \mathrm{C}$. The lowest values were observed in Kauz/Altar84//Ads, Mon's'/Ald's'//Bow's', Pfau/Milan, Adana-99, and Ures-Bow's' while the highest CT values were remarked in Croc1/Aegilops squarrosa, Kauz/Weawer, Saar, Trap1/Bow//Milan/3/Bau, and Weawer/WL 3926 (Figure 2).

In 2003 to 2004 growth season, although genotypes 


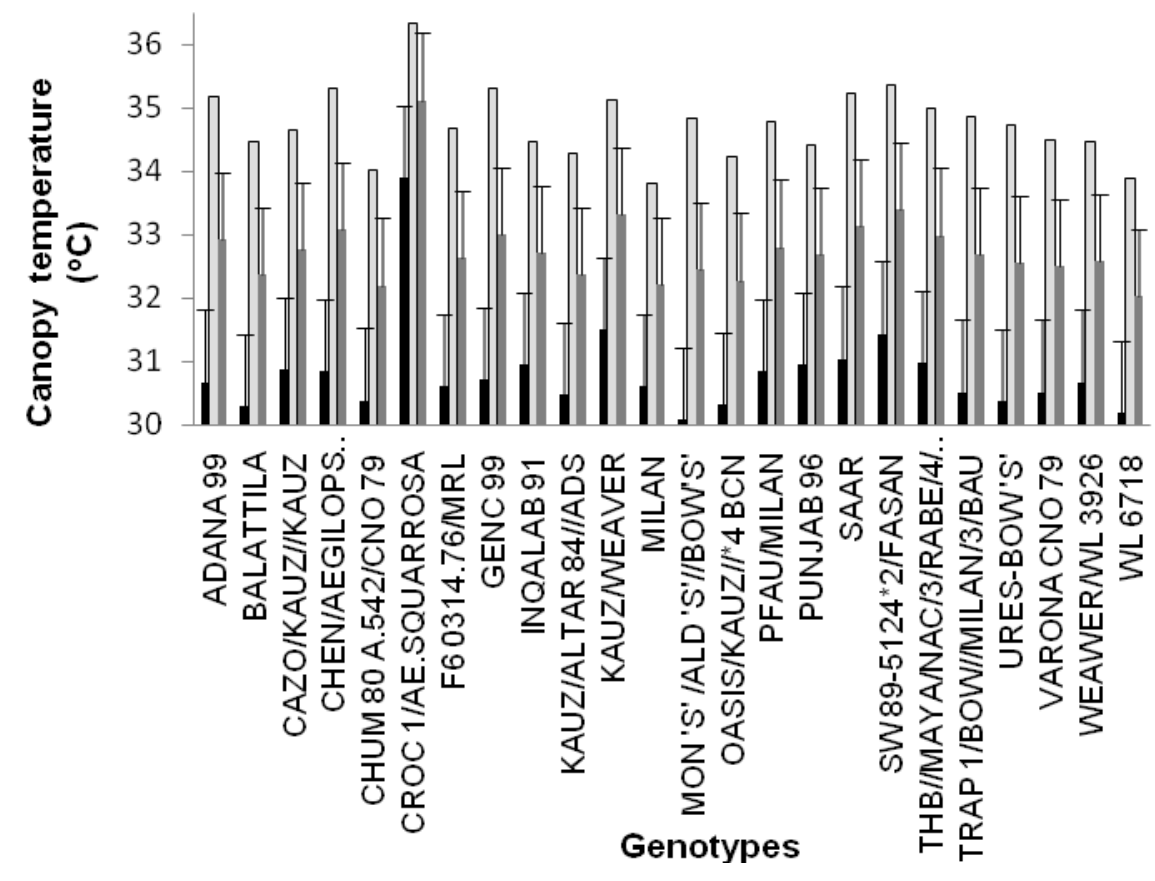

Figure 3. Changes in the measurements of the canopy temperatures of 24 bread wheat genotypes at the complete heading stage (ZGS 5.8) in 2003 to 2004 growth season. Error bars indicate LSD at 0.05 probability for T1 measuring time (11 April, 2004; 12:00 to 13:00 h) and mean of T1 and T2. Genotypes did not show any significant differences at T2 measuring time (11 April, 2004; 14:00 to 15:00 h).

showed statistically non-significant differences for canopy temperature (CT) measurements at $14.00 \mathrm{~h}$, they had significant differences at $12.00 \mathrm{~h}$ and avarage of measurement times $(12.00$ and $14.00 \mathrm{~h})$ at the end of heading stage (ZGS 58). CT ranged from 30.08 to $33.90^{\circ} \mathrm{C}$ at $12.00 \mathrm{~h}$, from 33.82 to $36.34^{\circ} \mathrm{C}$ at $1400 \mathrm{~h}$, and from 32.03 to $35.12^{\circ} \mathrm{C}$ for avarage of measurements. The lowest CT measurements at $12.00 \mathrm{~h}$ were observed in Mon's'/Ald's'//Bow's', WL 6718, Balattila, Oasis/Kauz//*4BCN, Ures-Bow's', and Chum80A.542/Cno79 although the highest CT measurements occurred in Croc1/Aegilops squarrosa, Kauz/Weawer, and SW 89-5124*2/Fasan. At $14.00 \mathrm{~h}$, genotypes Milan, WL 6718, Chum80A.542/Cno79, Oasis/Kauz//* $4 \mathrm{Bcn}$, and Kauz/Altar 84//Ads showed the lowest CT values although Croc1/Aegilops squarrosa, SW 89-5124*2/Fasan, Genc-99, and Chen/Aegilops squarrosa were pointed out by their highest CT measurements. For mean of measurement times, the lowest CT values were observed in WL 6718, Chum80A.542/Cno79, Milan, Oasis/Kauz//* $4 \mathrm{Bcn}$, Balattila, and Kauz/Altar 84//Ads while the highest CT values belonged to Croc1/Aegilops squarrosa, SW 89$5124^{*} 2 /$ Fasan, Kauz/Weawer, Saar, Chen/Aegilops squarrosa, and Genc-99 genotypes (Figure 3).

Overall mean variations (growth seasons, measuring times and growth stages) of the canopy temperatures of bread wheat genotypes were significantly different (Figure 4). As shown in Figure 4, the range of averall canopy temperatures of the genotypes was 33.29 to $36.34^{\circ} \mathrm{C}$. The lowest canopy temperature values were observed in Kauz/Altar $84 / /$ Ads $\left(33.29^{\circ} \mathrm{C}\right)$, Varona Cno $79 \quad\left(33.62^{\circ} \mathrm{C}\right), \quad$ Mon's'/Ald's'//Bow's' $\left(33.65^{\circ} \mathrm{C}\right)$, and WL6718 $\left(33.66^{\circ} \mathrm{C}\right)$ genotypes. On the other hand, the highest CT measurements were obtained from Croc1/Aegilops squarrosa $\left(36.34^{\circ} \mathrm{C}\right)$ and Kauz/Weawer $\left(35.54^{\circ} \mathrm{C}\right)$. Siddique et al.'s (2000) findings (23.89 to $29.1^{\circ} \mathrm{C}$ ) were lower than the present study. In 2002 to 2003 season, maximum air temperatures had risen upto $36.8^{\circ} \mathrm{C}$ despite the favorable soil moisture conditions. Thus, CT of the genotypes had increased, too. Fahliani and Assad (2005) found similar CT values (26.0 to $42.3^{\circ} \mathrm{C}$ ) except a few cultivars under non-drought stress conditions. They also obtained much higher CT values $\left(50.9\right.$ to $\left.54.5^{\circ} \mathrm{C}\right)$ under drought stress conditions. However, in the present study, CT mean values of the genotypes were not as high as Fahliani and Assad (2005). However, 2003 to 2004 season were not favorable for the precipitation. For this reason, the yield of this season was lower than the previous season (Bahar and Yildirim, 2010). In addition, maximum air temperatures of nearly $30^{\circ} \mathrm{C}$ can negatively affect the 


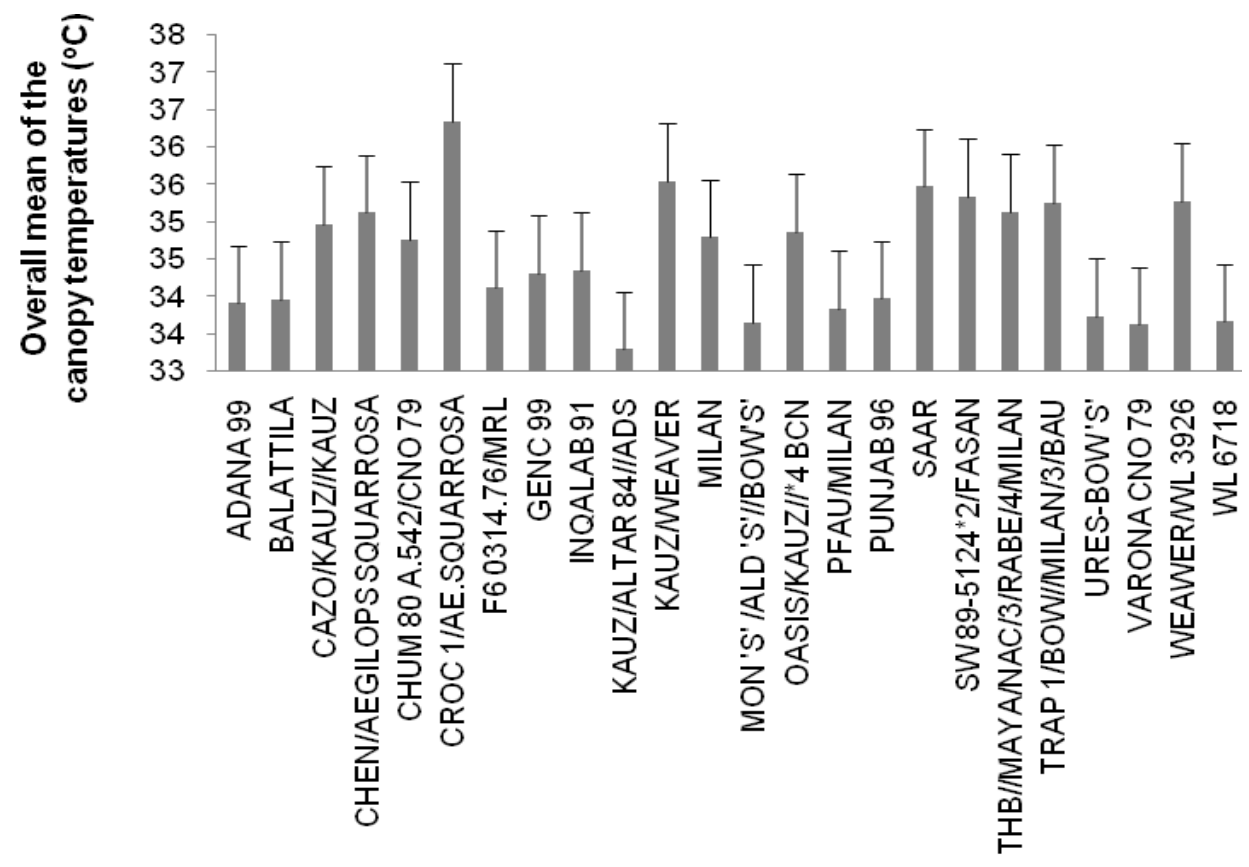

Genotype

Figure 4. Changes in overall canopy temperatures (as mean of both growth seasons) of 24 bread wheat genotypes in 2002 to 2003 and 2003 to 2004 growth seasons. Error bars indicate LSD at 0.05 probability.

grain formation at heading stage under moisture stressed condition in 2002 to 2003 season. Although CT values of the season of 2002 to 2003 (Figure 2) were higher than the following season (Figure 3), wheat genotypes were not affected from the high temperatures because of the favorable soil moisture presence. Thus, plants had possibility of cooling by the transpiration of the stomata. In this way, at all environments (Figure 4), genotypes Kauz/Altar 84//Ads, Varona Cno 79, and Mon's'/Ald's'//Bow's' had the lowest CT values and they can be used as heat tolerant material in breeding programmes.

\section{Canopy temperature depression}

Canopy temperature depression (CTD) measured at the end of heading stage in 2003 to 2004 growth season did not vary significantly among the genotypes at both measuring times (12.00 and $14.00 \mathrm{~h})$ and in terms of their mean. (CTD ranged from -2.05 to $0.18^{\circ} \mathrm{C}$ at $12.00 \mathrm{~h}$, from -2.70 to $-0.80^{\circ} \mathrm{C}$ at $14.00 \mathrm{~h}$, and from -2.38 to $0.69^{\circ} \mathrm{C}$ at mean hours. At both measuring time, Kauz/Altar 84//Ads and WL 6718 showed high CTD value in contrast to Croc1/Aegilops squarrosa, Saar, SW 89$5124^{\star} 2 /$ Fasan, and Kauz/Weawer (Figure 5). While the findings of Rees et al. (1993) in bread wheats were 3.54 to $5.10^{\circ} \mathrm{C}$ at the stage of pre-anthesis, 3.16 to $4.61^{\circ} \mathrm{C}$ at post-anthesis; our results showed negative values for
CTD. It is estimated that plants in the complete heading stage (ZGS 5.8) have closed their stomata to inhibit the water lost from the leaves because of the limited soil mositure and high temperatures. Thus, the flag leaves have not lost the water from the stomata by transpiration, and not become cooler; herewith, CTD's of the genotypes have mostly showed negative values. Bahar et al. (2008) have reported similar results.

\section{Stay green duration}

In 2002 to 2003 growth season, stay green durations (SGD) of the genotypes showed statistical significant differences, and varied from 162.5 to 167.8 days (Figure 6). In this connection, Weawer/WL 3926, Inqalab 91, Cazo/Kauz//Kauz, and SW 89-5124*2/Fasan had the lowest SGD while Varona Cno 79, Adana 99, Punjab 96, Ures-Bow 's', and Kauz/Altar 84//Ads had the highest SGD. Unlike Kumari et al.'s (2007) research, this study exhibits a new approach on SGD. According to new model, there was a statistical significant relation between CT and SGD. In addition, this relation will be detailed in the "Correlations" sub-title.

\section{Correlations}

As shown in Table 1, there were negative correlations 


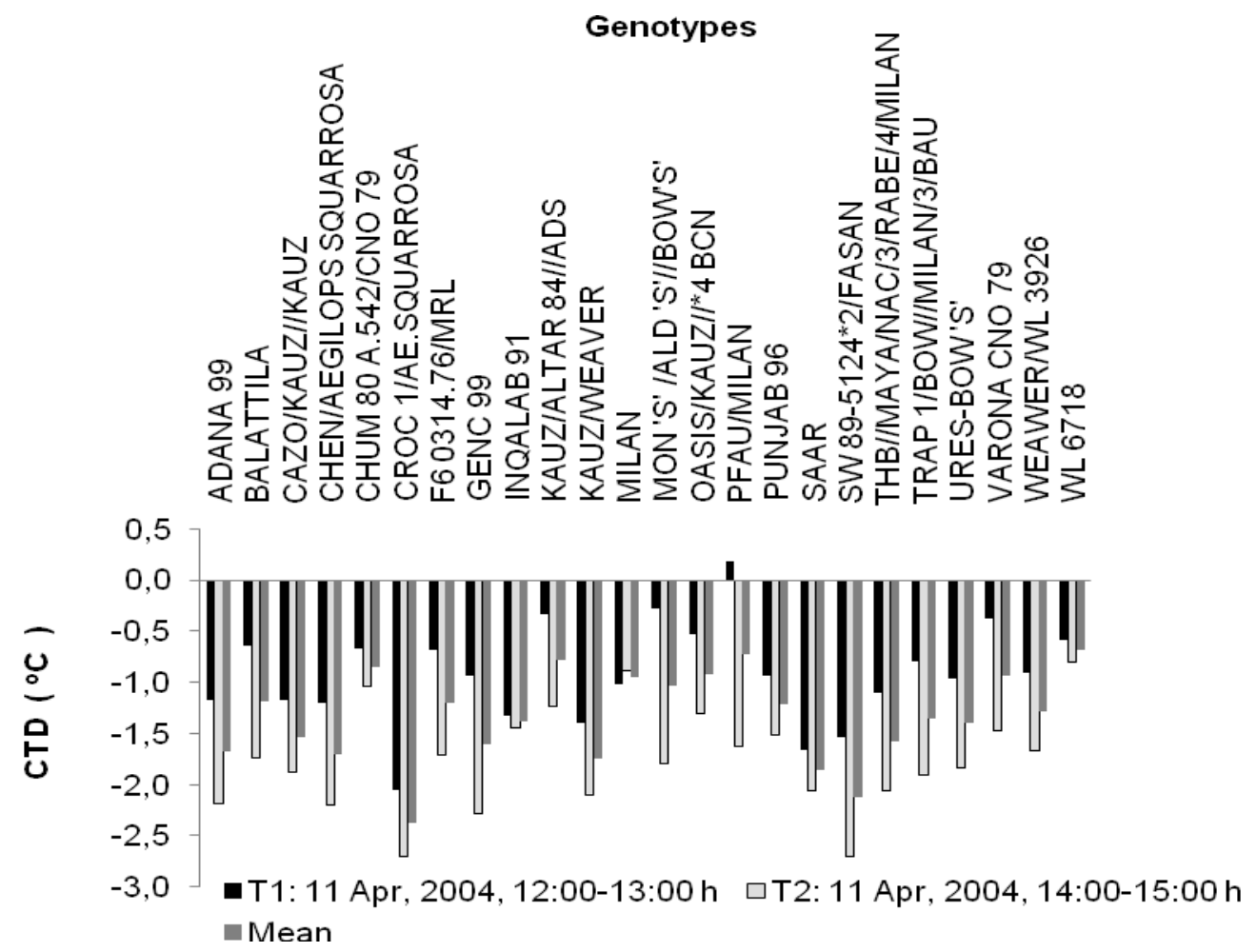

Figure 5. Changes in the measurements of the canopy temperature depression (CTD) of 24 bread wheat genotypes in 2003 to 2004 growth season. LSD is not significant at 0.05 probability for both measuring times (T1 and T2) and their mean.

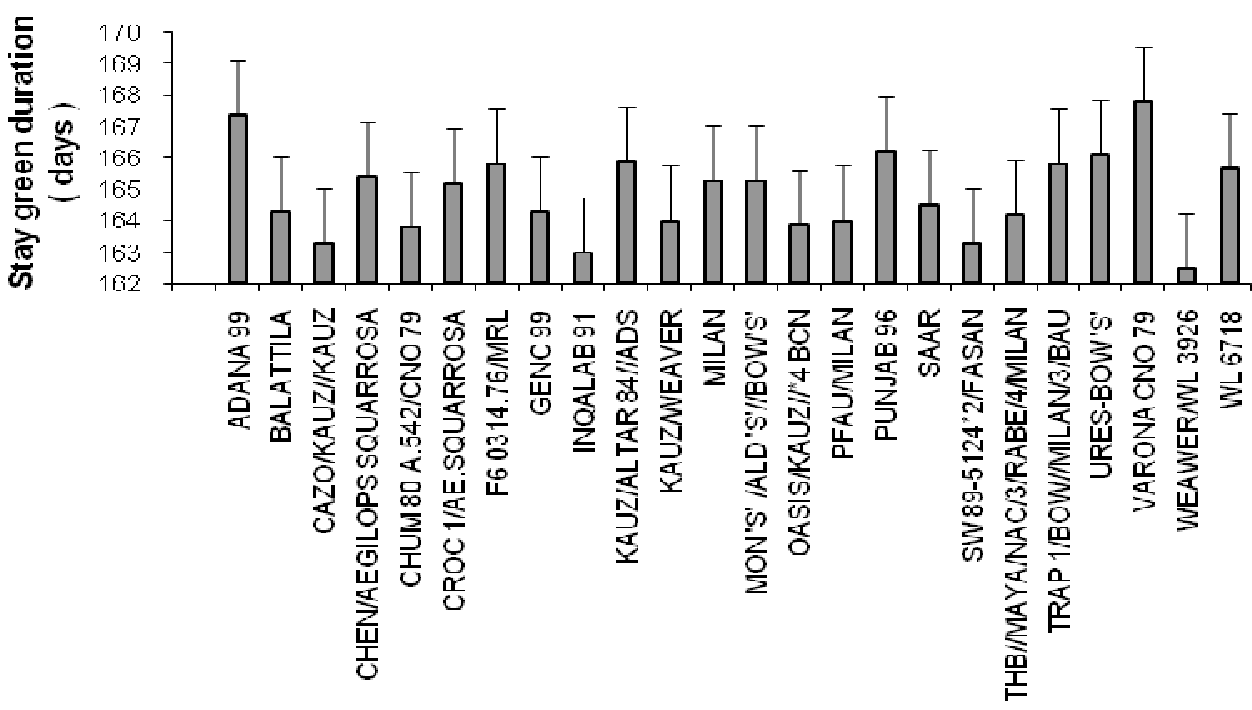

Genotypes

Figure 6. Variations for stay green durations of 24 bread wheat genotypes in 2002 to 2003 growth season. Error bars indicate LSD at 0.05 probability.

between grain yield (GY) and canopy temperature (CT) at all measurements such as in 2002 to $2003(r=-0.354$ NS $)$, in 2003 and $2004\left(r=-0.531^{* *}, P \leq 0.01\right)$, and overall $\left(r=-0.647^{* * *}, P \leq 0.001\right)$. Gutierrez et al. (2010) found a strong relationship between yield and canopy temperature at grain filling period. In addition, Singh and 
Table 1. Correlation coefficients $(r)$ between grain yield (GY) and morpho-physiological traits $\left(g_{s}\right.$, stomatal conductance; CT, canopy temperature; CTD, canopy temperature depression; SGD, stay green duration) in twenty-four spring bread wheat genotypes in 2002 to 2003 and 2003 to 2004 growth seasons.

\begin{tabular}{lccc}
\hline Growth season & Variable & By variable & r \\
\hline \multirow{2}{*}{$2002-2003$} & GY & CT & -0.354 \\
& GY & SGD & 0.332 \\
& CT & SGD & $-0.523^{* *}$ \\
& GY & CTD & $0.706^{* * *}$ \\
$2003-2004$ & GY & gs & -0.076 \\
& GY & CT & $-0.531^{* *}$ \\
& gs & CTD & -0.138 \\
Overall & CT & CTD & $-0.846^{* * *}$ \\
\hline
\end{tabular}

${ }^{* *},{ }^{* * *}$ Significant at 0.01 and 0.001 probability levels, respectively.

Kanemasu (1983) found negative significant correlation ( $r$ $=-0.81 ; P \leq 0.05$ ) between GY and CT in the afternoon measurements in pearl millet genotypes under irrigated conditions. They announced that pearl millet genotypes showed significantly higher yield with warmer canopy temperature (CT) under irrigated conditions than with cooler CT under non-irrigated conditions. Similarly, in the present study, 2002 to 2003 growth season that had very hot temperatures over $30^{\circ} \mathrm{C}$ along 22 days in the grain filling period for soil moisture was very favorable for bread wheat genotypes. 2003 to 2004 growth season were even good for temperature (only 5 days were over $30^{\circ} \mathrm{C}$ ), soil moisture was limited in grain filling period. Thus, the grain yield of the genotypes in the first season was conspicuously higher than in the second season.

There was a positive non-significant correlation $(r=$ 0.332 ) between $\mathrm{GY}$ and stay green duration (SGD). SGD was highly negative correlated with CT $(r=-0.523, P \leq$ 0.01 ). These relations have showed that bread wheat genotypes with cooler leaf present high grain yield and have longer SGD. Kumari et al. (2007) have pointed out similarly to this study that leaf area under decline (heat stress) as a new parameter of the stay green was srongly correlated $(r=0.90)$ with canopy temperature depression (CTD). Indeed, genotypes with high CTD had cooler flag leaves in our study, and there was a high significant negative correlation $\left(r=-0.846^{* * *}, P \leq 0.001\right)$ between CTD and CT in 2003 to 2004 growth season. CTD was also clearly associated $\left(r=0.706^{* * *}, P \leq 0.001\right)$ with $G Y$. Similar findings were announced by Amani et al. (1996), Ayeneh et al. (2002), Munjal and Rana (2003), Balota et al. (2008), Bahar et al. (2008) and Gutierrez et al. (2010).

According to obtained results, CT and CTD can be used a rapid tool to select stable and high yielding bread wheat genotypes under heat stressed conditions in the field. SGD can also be used as a selection criterion with
CT or CTD under environmental stress conditions. When genotypes which have cooler canopy temperature are taken into consideration with stay green trait, it is advised that Kauz/Altar 84//Ads, Varona Cno 79, Mon's'/Ald's'//Bow's', and WL6718 be used as heat tolerant genetypes in wheat breeding programs.

\section{ACKNOWLEDGEMENTS}

The study was supported by the Research Foundation of Cukurova University and Field Crops Department. We thank to Prof. Mujde KOC, Prof. Ibrahim GENC, and Assoc. Prof. Celaleddin BARUTCULAR. Also thanks to Nazli UYSAL for language corrections.

\section{REFERENCES}

Acevedo E, Nachit M, Ortiz-Ferrara G (1991). Effects of heat stress on wheat and possible selection tools for use in breeding for tolerance. In: Saunders, DA (ed.) Wheat for the Nontraditional Warm Areas. CIMMYT, Mexico, pp. 401- 421.

Amani I, Fischer RA, Reynolds MP (1996). Canopy temperature depression association with yield of irrigated spring wheat cultivars in a hot climate. J. Agron. Crop Sci., 176(2): 119-129.

Anjum F, Wahid A, Javed F, Arshad M (2008). Influence of foliar applied thiurea on flag leaf gas exchange and yield parameters of bread wheat (Triticum aestivum L.) cultivars under salinity and heat stress. Int. J. Agric. Biol., 10(6): 619-626.

Ayeneh A, Ginkel M, Reynolds MP, Ammar K (2002). Comparison of leaf, spike, peduncle, and canopy temperature depression in wheat under heat stress. Field Crops Res., 79: 173-184.

Bahar B, Yidirim M (2010). Heat and drought resistances criteria in spring bread wheat: Drought resistance parameters. Sci. Res. Essays., 5(13): 1742-1745.

Bahar B, Yildirim M, Barutcular C (2009). Relationships between stomatal conductance and yield components in spring durum wheat under Mediterranean conditions. Notulae Botanicae Horti Agrobotanici Cluj-napoca, 37(2): 45-48.

Bahar B, Yildirim M, Barutcular C, Genc I (2008). Effect of canopy temperature depression on grain yield and yield components in bread 
and durum wheat. Notulae Botanicae Horti Agrobotanici Cluj-napoca, 36(1): 34-37.

Balota M, Payne WA, Evet SR, Lazar MD (2007). Canopy temperature depression sampling to assess grain yield and genotypic differentation in winter wheat. Crop Sci., 47: 1518-1529.

Balota M, Payne WA, Evet SR, Peters TR (2008). Morphological and physiological traits associated with canopy temperature depression in three closely related wheat lines. Crop Sci., 48: 1897-1910.

Ban bella M, Paulson GM (1998). Efficiency of treatments for delaying senescence of wheat leaves: II. Senescence and grain yield under field conditions. Agron. J., 90: 332-338.

Bhullar SS, Jenner CF (1985). Differential responses to high temperature of starch and nitrogen accumulation in the grain of four cultivars of wheat. Aust. J. Plant Physiol., 12: 363-75.

Blum A (1988). Plant Breeding for Stress Environments. CRC Press, Boca Raton, p. 72.

Blum A, Neguyen CY (1997). The effect of plant size on wheat response to agents of drought stress. II. Water deficit, heat and ABA. Plant Physiol., 24: 35-41.

Curtis BC (2002). Wheat in the world. In: Curtis, BC, Rajaram S, Macpherson HG (eds.) Bread wheat improvement and production. FAO Plant Production and Protection Series. p. 30. Rome.

Delgado MI, Reynolds MP, Larque-Saavedra A, Nava ST (1994). Genetic Diversity for Photosynthesis in Wheat under Heat Stressed Field Environments and Its Relation to Productivity. Wheat Special Report, 30: 17.

Donmez E, Sears RG, Shroyer JP, Paulsen GM (2001). Genetic gain in yield attributes of winter wheat in the great plains. Crop Sci. Res., 41: 1412-1419.

Fahliani RA, Assad MT (2005). Evaluation of three physiological traits for selecting drought resistant wheat genotypes. J. Agric. Sci. Technol., 7: 81-87.

Fischer RA (1986). Physiological limitations to producing wheat in semitropical and tropical environments and possible selection criteria. In Proc. Int. Sym. Wheat for Tropical Environments. CIMMYT, Mexico, pp. 209-230.

Fischer RA, Rees D, Sayre KD, Lu ZM, Condon AG, Larque-Saavedra A (1998). Wheat yield progress is associated with higher stomatal conductance and photosynthetic rate, and cooler canopies. Crop Sci., 38(6): 1467-1475.

Ginkel M, Reynolds MP, Trethowan R, Hernandez E (2004). Can canopy temperature depression measurements help breeders in selecting for yield in wheat under irrigated production conditions? In: Proceedings of the $4^{\text {th }}$ International Crop Science Congress, Brisbane, Australia.

Gutierrez M, Reynolds MP, Raun WR, Stone ML, Klatt AR (2010). Spectral water indices for assessing yield in elite bread wheat genotypes under well-irrigated, water stressed, and high temperature conditions. Crop Sci., 50: 197-214.

Harding SA, Guikema JA, Paulsen GM (1990). Photosynthetic decline from high temperature stress during maturation of wheat. I. Interaction with senescence processes. Plant Physiol., 92: 648-653.

Jackson P, Robertson M, Cooper M, Hammer G (1996). The role of physiological understanding in plant breeding, from a breeding perspective. Field Crops Res., 49: 11-37.

JMP (2007). Introductory Guide, Release 7, SAS Institute Inc., Cary, NC, USA.

Koc M, Barutcular C, Genc I (2003). Photosynthesis and productivity of old and modern durum wheats in a Mediterranean Environment. Crop Sci., 43(6): 2089-2097.
Koc M, Barutcular C, Tiryakioglu M (2008). Possible heat-tolerant cultivar improvement through the use of flag leaf gas exchange traits in a Mediterranean Environment. J. Sci. Food Agric. Res., 88: 16381647.

Kumar U, Joshi AK, Kumari M, Paliwal R, Kumar S, Röder MS (2010). Identification of QTLs for stay green trait in wheat (Triticum aestivum L.) in the 'Chirya 3' $x$ 'Sonalika' population. Euphytica. 174: 437-445.

Kumari M, Singh VP, Tripathi R, Joshi AK (2007). Variation for staygreen trait and its association with canopy temperature depression and yield traits under terminal heat stress in wheat. In: Buck HT, Nisi JE, Salomon N (eds) Developments in Plant Breeding, Wheat Production in Stressed Environments. Springer Press, 12: 357.

Mohammadi V, Quannadha MR, Zali AA, Yazdi-Samadi B (2004). Effect of post anthesis heat stress on head traits of wheat. Int. J. Agric. Biol., 6 (1): 42-44.

Munjal R, Rana RK (2003). Evaluation of physiological traits in wheat (Triticum aestivum L.) for terminal high temperature tolerance. In: Proceedings of the Tenth International Wheat Genetics Symposium, Classical and Molecular Breeding, Poestum, Italy, 2(3): 804-805.

Ozkan H, Yagbasanlar T, Genc I (1998). Tolerance and stability studies on durum wheat under drought and heat stress conditions. Cereal Res. Commun., 26: 405-412.

Rees D, Sayre K, Acevedo E, Nava S T, Lu Z, Zeiger E, Limon A (1993). Canopy Temperatures of Wheat: Relationship with Yield and Potential as a Technique for Early Generation Selection. Wheat Special, 10: 32. Mexico,

Reynolds MP, Balota M, Delgado MIB, Amani I, Fischer RA (1994). Physiological and morphological trais associated with spring wheat yield under hot, irrigated conditions. Aust. J. Plant Physiol., 21: 717730.

Reynolds MP, Nagarajan S, Razzaque MA, Ageeb OAA (2001) Breeding for adaptation to environmental factors, heat tolerance. In: Reynolds MP, Ortiz-Monasterio I, McNab A (eds.) Application of physiology in wheat breeding, Cimmyt, Mexico, p. 124-125.

Siddique MRB, Hamid A, Islam MS (2000). Drought stress effects on water relations of wheat. - Bot. Bull. Acad. Sin., 41: 35-39.

Singh P, Kanemasu ET (1983). Leaf and canopy temperatures of pearl millet genotypes under irrigated and non-irrigated conditions. Agron. J., 75: 497-501.

Stone PJ, Nicolas ME (1994). Wheat cultivars vary widely in their responses of grain yield and quality to short periods of post-anthesis heat stress. Aust. J. Plant Physiol., 21: 887-900.

Thomas H, Smart CM (1993). Crops that stay green. Annal. Appl. Biol., 123: 193-229.

Yıldııım M, Bahar B, Koç M, Barutçular C (2009). Membrane thermal stability at different developmental stages of spring wheat genotypes and their diallel cross populations. Tarim Bilimleri Dergisi, 15 (4): 293300

Yıldırım M, Kılıc H, Kendal E, Karahan T (2011). Applicability of chlorophyll meter readings as yield predictor in durum wheat. J. Plant Nutr., 34(2): 151-164.

Zadoks JC, Chang TT, Konzak CF (1974). A decimal code for growth stages of cereals. Weed Res., 14: 415-421. 